\title{
A COMPARISON OF HYDROGEN VS. HELIUM GLOW DISCHARGE EFFECTS ON FUSION DEVICE FIRST-WALL CONDITIONING
}

\author{
H. F. Dylla \\ PPPL- -2642 \\ Princeton Plasma Physics Laboratory, Princeton University \\ Princeton, NJ 08543 \\ DEB9 016954
}

\section{ABSTRACT}

Hydrogen- and deuterium-fueled glow discharges are used for the initial conditioning of magnetic fusion device vacuum vessels following evacuation from atmospheric pressure. Hydrogenic glow discharge conditioning (GDC) significantly reduces the near-surface concentration of simple adsorbates such as $\mathrm{H}_{2} \mathrm{O}, \mathrm{CO}$, and $\mathrm{CH}_{4}$, and lowers ioninduced desorption coefficients by typically three orders of magnitude. The time evolution of the residual gas production observed during hydrogen-glow discharge conditioning of the carbon first-wall structure of the TFTR device is similar to the time evolution observed during hydrogen GDC of the initial first-wall configuration in TFTR, which was primarily stainless steel. Recently, helium GDC has been investigated for several wall-conditioning tasks on a number of tokamaks including TFTR. Helium GDC shows negligible impurity removal with stainless steel walls. For impurity conditioning with carbon walls, helium GDC shows signiticant desorption of $\mathrm{H}_{2} \mathrm{O}, \mathrm{CO}$. and $\mathrm{CO}_{2}$; however, the total desorption yield is limited to the monolayer range. In addition, helium GDC can be used to displace hydrogen isotopes from the near-surtace region of carbon first-walls in order to lower hydrogenic retention and recycling.

This paper was presented at the AVS Topical Conference on surface MASTER Conditioning of Vacuum Systems, Los Angeles, CA. April 3-5, 1989 
INTROOUCTION

Glow discharge conditioning (GDC) is used routinely for first-wall conditioning of most magnetic fusion devices. GDC methodology and the results of GDC studies from various studies on tusion devices and accelerator systems have been reviewed recently. ${ }^{1}$ This paper focuses on two comparisons of particular interest to the fusion community, a comparison of glow discharge effects with predominantly metallic or predominantly carbon first walls, and a coinparison of hydrogenic vs. helium-fueled glow discharges on the same two wall materials.

Glow discharge conditioning can be applied to magnetic fusion devices for several possible benefits. The primary benefit of GDC is the reduction of the common low-z impurities (i.e., $C$ and $O$, but also $S, C l$, and $N$ ) from the surface and near-strface regions of the tirst wall. Proper conditioning of the first wall means that the usual surface concentrations of these impurities are reduced to minimize the contamination of high temperature plasnias when the boundary plasma interacts with the first wall. Quantitatively, sufficient conditioning is signaled by: 1) significant reductions in the partial pressures of volatile impurity species produced in the glow discharge; 2) reductions of surface impurity concentrations; and 3 ) reductions in ion-induced desorption coeticients.

A secondary benefit of GDC, which is particularly useful for particle control in tokamaks, is the replacement or reduction of the surface cor:centration of hydrogenic species in the first wall. For example, deuterium-tueled GDC can be used to deplete partially a hydrogen saturated first wall by isotopic - rchange, or helium GDC can be used to partially deplete rear-surtace $r$ : z'ogenic species within the range of the helium ions. The particle contrc. Jenefits of GDC pertain to carbon firstwalls applications where the nydrogenic saturation concentrations $(\mathrm{H} / \mathrm{C} \sim 0.4)$ are sufficiently large to cause long hydrogen isotope exchange times ${ }^{2}$ and exhibit wall pumping effects. ${ }^{3}$ For stainless steel walls where hydrogen/metal concentrations are less than 0.01 , significant hydrogenic exchange times or wall pumping effects are not seen. ${ }^{4}$ 
A third beneficial effect of GDC is arc conditioning which is seen in applications to both metallic and carbon first walls. Glow discharge exposure generally will reduce arc initiation sites exponentially with exposure time, 5,6 thus effectively eliminating unipolar arcs as an impurity introduction source during subsequent high power plasma exposure.

\section{EXPERIMENTAL CONSIDERATIONS}

One of the significant advantages of GDC as an in-situ conditioning technique for magnetic fusion devices for any large, complicated vacuum vessel) is the simplicity of the required hardware for implementation. In addition to a gas inlet source and a high throughput pump (which are usually standard equipment on a magnetic fusion vessel), an anode structure that can be introduced into the vessel, and a suitable power supply for initiating and sustaining the glow discharge are required. General remarks on suitable electrode structures and the concerns relative to using dc, $\mathrm{r}$, or microwave excitation are given in Ref. 1 . For the purpose of quantitative comparisons of hydrogenic vs. helium-fueled GDC, we will focus on the simplest configuration, the dc excited glow discharge.

The glow discharge has been described in many classic studies of gaseous electronics. ${ }^{7}$ The basic glow discharge regimes are often illustrated in terms of the I-V characteristic (Fig. 1) of a gas discharge between two equal-size electrodes, with an arbitrary length discharge (the so-called "positive column") between the electrodes.

The electrode situation is different for glow discharge conditioning of fusion vessels. Firstly, the anode-cathode geometries are vastly different: the vessel is the cathode and surrounds the discharge; and the anode is usually orders of magnitude smaller in size and is introduced within the vessel. Nevertheless, similar plasma regimes are observed with the typical fusion vessel GDC configuration as found with the classic glow discharge configuration. 
A glow discharge may be initiated in a fusion device at a low current appropriale to the "normal glow" regime where the cathode fall potential $\left(V_{c}\right)$ is independent of the discharge current. ${ }^{7}$ A glow discharge cannot be sustained below a minimum current density to the cathode, typically $\sim 1 \mu \mathrm{A} / \mathrm{cm}^{2}$, which is necessary to sustain the discharge by secondary electron emission. The more useful regime for GDC is the abnormal "glow regime" where $V_{C}$ is proportional to the discharge current since larger currents and thus larger vessel surface ion fluxes can be sustained. However, the discharge current cannot be increased to arbitrarily large values because of two limitations. One limitation occurs when electrode current densities exceed $100 \mu \mathrm{A} / \mathrm{cm}^{2}$, causing the discharge to make a transition to the arc regime, which is totally inappropriate for vessel conditioning because of deposition of electrode materials. Secondly, bofore this arc transition current is reached, the current density within the discharge may be sufficient to reionize volatile desorption products preventing their removal from the vessel. This situation has been analyzed by a number of authors ${ }^{1,8,9}$ leading to reaction product rate equations such as:

$$
v \frac{d P}{d t}=k_{s}-\left(k_{a}+k_{i}\right)-S P
$$

where $\mathrm{k}_{\mathrm{S}}$ is the surface reaction rate for the formation of the volatile reaction product due to the glow discharge ion bombardment, $k_{a}$ is the rate of readsorption, $k_{j}$ is the rate of ionization in the discharge, and the removal rate from the vessel is given by the product SP. A useful practical limiting case of Eq. (1) occurs when the system pumping speed (S) is large compared to $k_{a}$ and $k_{i}$, and the reaction product partial pressure $(P)$ becomes proportional to the cathode ion flux under quasisteady-state conditions. ${ }^{1}$

The above remarks show the typical range of available cathodic current densities for dc-driven abnormal glow discharges is of the order of $1-100 \mu \mathrm{A} / \mathrm{cm}^{2}$, or equivalently, singly ionized wall fluxes of $5 \times 10^{12}-5 \times 10^{14}$ ions $/ \mathrm{cm}^{2} \mathrm{sec}$. The heat capacity of the anode, which must withstand the power input of the concentrated electron flux over the 
smaller anode area, may restrict the high current limit to a smaller value than necessary to drive $100 \mu \mathrm{A} / \mathrm{cm}^{2}$ onto the cathode (wall).

Typical experimental parameters for hydrogen (deuterium) and helium-fueled GDC are given in Table 1.

\section{TABLE 1: GDC Parameters}

\begin{tabular}{|c|c|c|}
\hline Gas Type & $H(D)$ & He \\
\hline voltage (V) & 400 & 300 \\
\hline $\begin{array}{l}\text { current density } \\
\left(\mu \mathrm{A} / \mathrm{cm}^{2}\right)\end{array}$ & 10 & 10 \\
\hline $\begin{array}{l}\text { pressure } \\
\text { (mtorr) }\end{array}$ & 5 & 5 \\
\hline $\begin{array}{l}\text { fluence }\left(\mathrm{cm}^{-2}\right) \\
\text { wall temperature }\end{array}$ & $10^{19}$ & $10^{17}-10^{19}$ \\
\hline stainless steel & $25-250$ & $n / a$ \\
\hline carbon & $25=350$ & $25-350$ \\
\hline
\end{tabular}

The suggested total fluence and range of applicable wall temperatures shown in Table 1 are based on the results of GDC studies in a number of devices, some of which are described in the next section.

\section{COMPARISON OF HYDROGEN vS. HELIUM GDC ON STAINLESS STEEL}

Hydrogen- or deuterium-fueled GDC is often used for the initial conditioning of fusion devices following the evacuation of the vessel from atmospheric pressure. ${ }^{1}$ Figure 2 shows an example for the time dependence of the primary residual gases $\left(\mathrm{H}_{2} \mathrm{O}, \mathrm{CH}_{4}\right.$, and $\left.\mathrm{CO} / \mathrm{C}_{2} \mathrm{H}_{2}\right)$ produced during $\mathrm{H}-\mathrm{GDC}$ of the TFTR device during an early experimental phase when the first wall was stainless steel and Inconel. The approximate $1 \mathrm{~A}$ time dependence is consistent with the hypothesis that diffusion of carbon and oxygen in the near-surface ( $520 \mathrm{~nm}$ ) region of the steel is the rate-limiting step for reactant production. 1,5,10 
On the basis of data such as shown in Fig. 2, a hydrogenic ion fluence of $10^{19} \mathrm{~cm}^{-2}$ has been suggested as a practical endpoint for GDC of stainless steel surfaces. At this endpoint (which is after approximately $100 \mathrm{hrs}$. of GDC for the $15 \mathrm{~A}$ do glow discharges used in TFTA), an integrated quantity of carbon and oxygen equal to $\sim 100$ monolayers has been volatilized and removed from the vessel. The ioninduced desorption coefficients, inferred from the ratio af desorbed molecular flux to wall-averaged $\mathrm{H}^{+}$flux, fall from near unity at GDC initiation to $<10^{-3}$ at the $10^{19} \mathrm{~cm}^{-2}$ endpoint.

The surface chemistry of $\mathrm{H}_{2} \mathrm{O}$ production during hydrogen discharge conditioning of stainless steels is well understood. A model first proposed by Dietz et al. ${ }^{11}$ involving the reduction of iron oxides, has been supported by subsequent surface studies by Staib et al. ${ }^{12}$ and Dylla. ${ }^{13}$ Possible mechanisms for the formation of the observed hydrocarbon reaction products (i.e., $\mathrm{CH}_{4}, \mathrm{C}_{2} / \mathrm{H}_{4}$, atc.) have been described by Rye. ${ }^{14}$ The surface chemical mechanisms responsible for the production of $\mathrm{CO}$ (and to a lesser extent $\mathrm{CO}_{2}$ ) during $\mathrm{H}^{+}$ bombardment of stainless stee! surfaces remain to be elucidated.

The fact that similar surface reaction products have been observed from stainless steel bombarded with low energy atomic hydrogen 15 demonstrates that the cleaning process is primarily dependent on atomic hydrogen reacting with carbon and oxygen in the near-surface region of the bombarded surface. Hydrogen GDC is relatively insensitive to the incident hydrogen energy because it is not a physical sputtering process. Measurements of the incident energy distribution of low pressure $\left(\sim 10^{-2}\right.$ torr) hydrogen glow discharges ${ }^{16,17}$ show that $90 \%$ of the ion fluence is due to $\mathrm{H}_{2}^{+}$, yielding incident protons on the cathode with energies of $V_{c} / 2$, which is typically less than $200 \mathrm{eV}$ and below the sputtering threshold for $\mathrm{H}^{+}$on stainless steel. ${ }^{18}$ Sputtering yields of $2 \times 10^{-3}$ have been measured by Winter ${ }^{19}$ for $225 \mathrm{eV} \mathrm{H}$ ions from a hydrogen glow discharge incident on an Inconel surface. 
The surface chemistry virtually disappears with helium glow discharge exposure of stainless steel surfaces, where in this case, the dominant surface processes are ion-induced desorption and physical sputtering. When helium GDC was applied to the stainless steel walls of TFTR, the reaction products were negligible in comparison to hydrogen GDC production. The helium ion-induced desorption yields during the GDC were observed to be at least a factor of ten smaller than the corresponding hydrogen GDC salues.

\section{COMPARISON OF HYDROGEN VS. HELIUM GDC ON CARBON}

During 1985, much of the stainless steel first-wall area of the TFTR device was covered with graphite tiles, which were part of an axisymmetric bumper limiter and neutral beam protective plates. 20 This resulted in approximately $30 \%$ of the first-wall area being covered with graphite tiles. During the subsequent year of high power plasma operation, the remaining stainless steel first-wall area became coated with an amorphous carbon layer $21-22$ due to plasma redeposition effects. Our experience with hydrogen GDC of TFTR with a carbon first wall was surprisingly similar to our experience with the stainless steel first wall. Figure 3 shows a recent hydrogen GDC campaign with the carbon first walt. The dominant reaction products $\left(\mathrm{CH}_{4}, \mathrm{H}_{2} \mathrm{O}\right.$, and $\left.\mathrm{CO} / \mathrm{C}_{2} \mathrm{H}_{4}\right)$ and the time dependence $(-1 / t)$ are similar for the two cases (Fig. 2 and Fig. 3). One minor difference noted with the carbon first wall is a richer hydrocarbon spectrum, $H_{m} C_{n}$. (Fig. 4) especially during the first few hours of GDC exposure.

The observation that a similar quantity of carbon and oxygen are removed from both the stainless steel and carbon first walls may be indicative of similar reservoirs of desorbable carbon and oxygen within the $\mathrm{H}^{+}$ion range on both surfaces. For the stainless sie日l surface the impurities to be removed are confined to the passivation oxide layer which is typically $20 \mathrm{~nm}$ in thickness. ${ }^{13}$ The incident $200 \mathrm{eV} \mathrm{H+}$ ions have a range of $<5 \mathrm{~nm}$ in stainless steel; however, the diffusivity is high at ambient temperatures enabling the implanted hydroger: to sample the entire oxide layer. 
For the carbon wall, the incident range for $200 \mathrm{eV} \mathrm{H} \mathrm{H}^{+}$ions is $\sim 6 \mathrm{~nm}$. The bulk diffusivity is small at ambient temperatures; however, pore surface migration ${ }^{2}$ may allow larger depths to be sampled by the implanted hydrogen. The major difference between the two firsi-wall materials with respect to impurity behavior is the targe bulk reservoir in graphite for potentially desorbable carbon and oxygen. The TFTR graphite material (POCO AXF-5O) is known to absorb approximately -1 torr-liter/gram quantities of atmospheric water vapor as measured by thermal desorption. ${ }^{23}$ The absorbed $\mathrm{H}_{2} \mathrm{O}$ desorbs from the carbon as $\mathrm{H}_{2} \mathrm{O}$ or $\mathrm{CO}$ depending on the graphite temperature. This large source of oxygen can be effectively removed by vacuum baking 23 at temperatures $>300^{\circ} \mathrm{C}$. Our experience shows that bakeout at $150^{\circ} \mathrm{C}$, or hydrogen GDC at $150^{\circ} \mathrm{C}$, is insufficient to deplete the bulk reservoir. ${ }^{24}$ TFTR required the development of an in-situ flash desorption technique (termed disruptive discharge cleaning ${ }^{21,24}$ ) in order to heat the carbon first wall to sufficient temperatures for effective bulk degassing.

Helium GDC on carbon exhibits a characteristic desorption spectrum (Fig. 5) which is notably distinguishable from both the case of hydrogen GDC on carbon or the uninteresting case of helium GDC on stainless steel. Oxygen containing molecules $\mathrm{CO}, \mathrm{CO}_{2}$, and $\mathrm{H}_{2} \mathrm{O}$ are the dominant desorption products. The time dependence of these desorption products exhibits an exponential behavior characteristic of ion-induced desorption of a surface species (see Fig. 6).

The integrated quantity of carbon and oxygen under the exponential portions of the desorption signals in Fig. 6 iepresents approximately a monolayer averaged over the $100 \mathrm{~m}^{2}$ of geometric first-wall area in TFTR.

The above result suggests that helium GDC should be useful for removal of surface contamination that might accumulate on a carbon first wall due to an extended break in plasma operations (i.e., overnight) or due to the effects of a plasma disruption. Such benefits have been documented on $\mathrm{JET}^{3}$ and DIIID. ${ }^{25}$ Recent DIIID operation has 
incorporated helium GDC between high power discharges to ensure uniformity of initial surface conditions. ${ }^{26}$ Helium GDC is used routinely in the JET, ${ }^{3}$ TEXTOR, 27 and TORE-SUPRA 28 tokamaks for impurity conditioning with minimal hydrogenic loading. In the JET device the immediate recovery from high power disruptions is possible if a short period ( $<1 \mathrm{hr}$ ) of helium GDC is applied to the first wall. ${ }^{29}$

The most practical application of helium GDC in tokamaks has been for the purpose of displacing hydrogen isotopes from the near-surface region of carbon first-wall structures. This application is a natural progression from the earlier use of helium ohmic discharges for hydrogen recycling control in TFTR, $30,31 \mathrm{JET}_{1}{ }^{3}$ and DIIID.25 Significant decreases in hydrogen recycling have been observed with the use of helium GDC in DIIID. 25,26 The technique has been proposed as a means of reducing the first-wall tritium retention in TFTR after proposed D-T experiments. ${ }^{32}$

The hydrogen isotope release from carbon under helium GDC is believed to be the result of helium and carbon ion-induced desorption processes. Ion-induced desorption cross sections for release of hydrogen (or deuterium) from graphite have been measured in a number of glow discharge and ion beam experiments. ${ }^{33-37}$ Typically, measured He ion-induced release cross sections are of the order of $10^{16} \mathrm{~cm}^{-2}$ at glow discharge energies ( $<1 \mathrm{keV}$ ) and decrease with increasing incident He ion energy. ${ }^{37}$

In TFTR, helium GDC has been applied to the carbon first wall with two contrasting wall conditiors 1) during a pulse discharge cleaning campaign; and 2) after the fir:: wall was fully conditioned and degassed by helium ohmic discharges 30,31 The helium GDC data in Fig. 6 correspond to the first case, wh:ch sampled the wall conditions partially through a pulse discharge cleaning campaign. The helium GDC had the temporary effect of improving the character of the PDC pulaes (i.e., decreased runaway electron production and radiative power) for a period of less than an hour. ${ }^{38}$ This improvement is assumed to be the result of the oxygen surface desorption noted above for He-GDC. The second 
helium GDC exposure, which occurred when the TFTR vessel was wellconditioned by helium ohmic discharges, had no observable effect on the subsequent high power plasma performance oven though a factor of two drop in CII emission, and a factor of two to four rise in metallic impurities were noted after the helium GDC exposure. The inability of $\mathrm{He} G D C$ to further decrease $H$-recycling below the minimum value $(R=0.5)$ achieved by $\mathrm{He}$ ohmic conditioning 30,31 may be indicative of the advantage of He ohmic conditioning in a limiter tokamak, where the particle flux is concentrated on high flux areas of the tirst wall.

\section{CONCLUSIONS}

Hydrogenic glow discharge cleaning is useful for the initial conditioning of magnetic fusion devices following evacuation from atmospheric pressure. The effectiveness of hydrogen $\mathrm{GDC}$ is similar for stainless steel or carbon first walls, although higher wall temperatures $\left(>300^{\circ} \mathrm{C}\right)$ are required for effective degassing of oxygen from carbon firstwall structures. Helium GDC is not useful for conditioning stainless steel walls. However, for carbon first walls, helium GDC can be used for the removal of surface oxygen impurities and for the displacement of hydrogenic species by ion-induced desorption from the near-surface region. 


\section{ACKNOWLEDGMFNTS}

The author thanks his colleagues in the magnetic tusion and accelerator communities who have contributed to these studies, especially, S. Cohen, J. Dietz, B. Doyle, J. Ehrenberg, R. Hawryluk, W. Hsu, P. LaMarche, R. Langley, D. Manos, A. Mathewson,

G. McCracken, D. Mueller, P. Staib, M. Ulrickson, F. Waelbroeck, W. Wampler, K. Wilson, and J. Winter.

This work supported by United States Department of Energy Contract No. DE-AC02-76-CHO3073. 


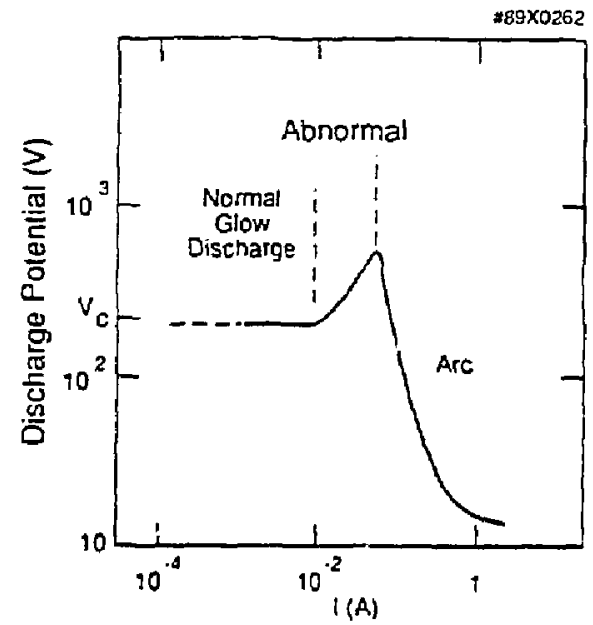

Fig. 1. Voltage ( $($ ) - Current (1) characteristics of the classical do glow discharge (adapted from Von Engle 7 .

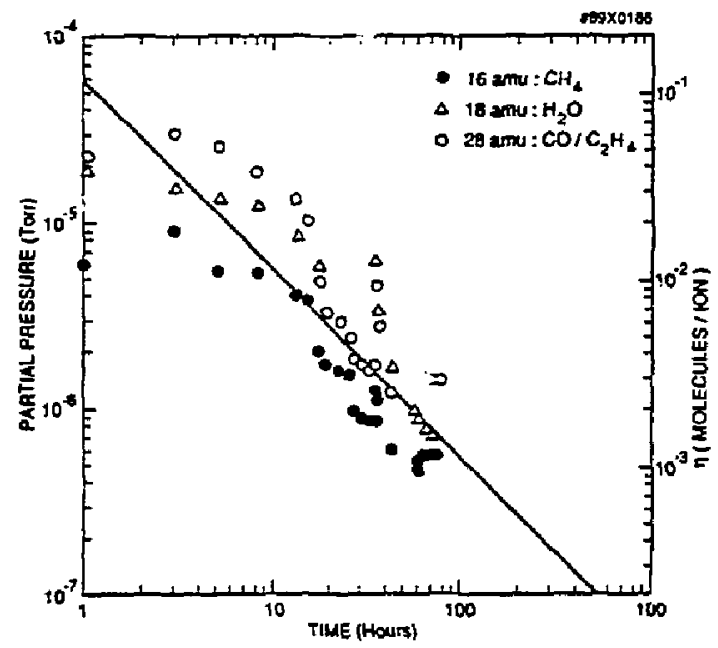

Fig. 2. Residual gas production during hydrogen discharge conditioning (GDC) of TFTR with a stainless steel first wall. 


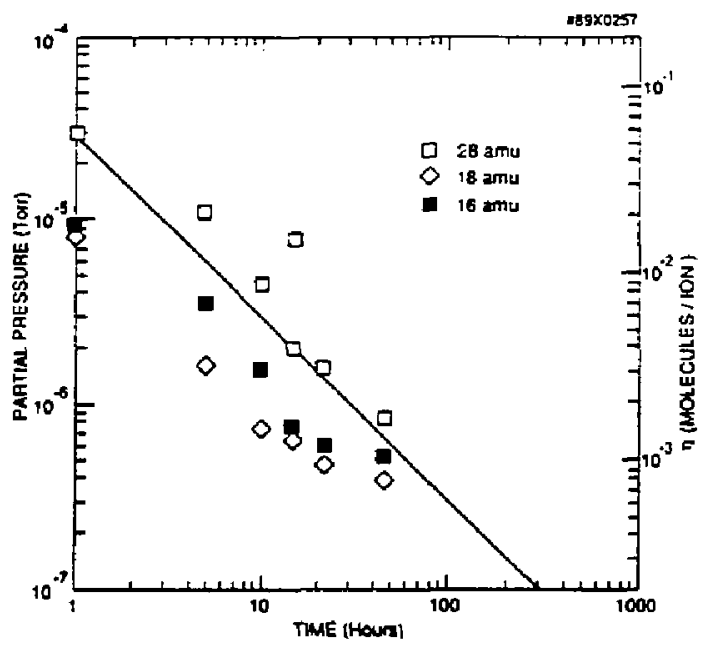

Fig. 3. Residual gas production during hydrogen GDC with a carbon first wall.

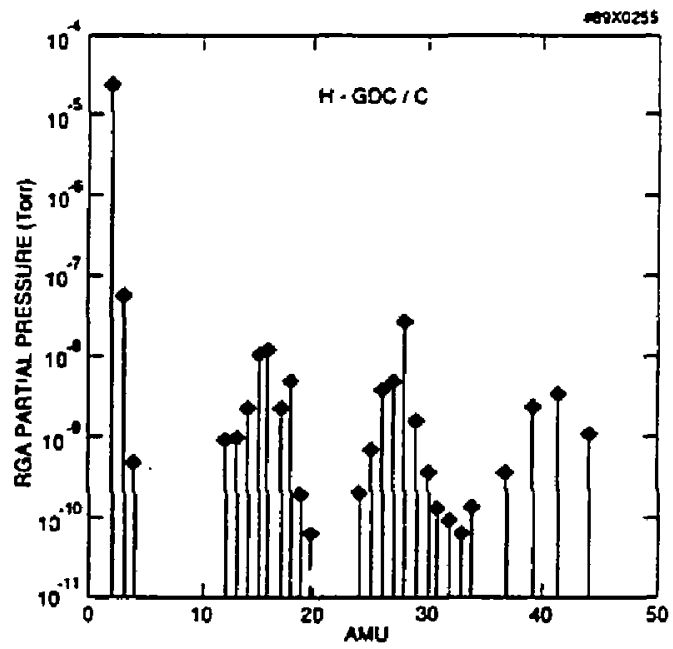

Fig. 4. Residual gas spectrum produced during hydrogen GDC of TFTR with a carbon first wall. 


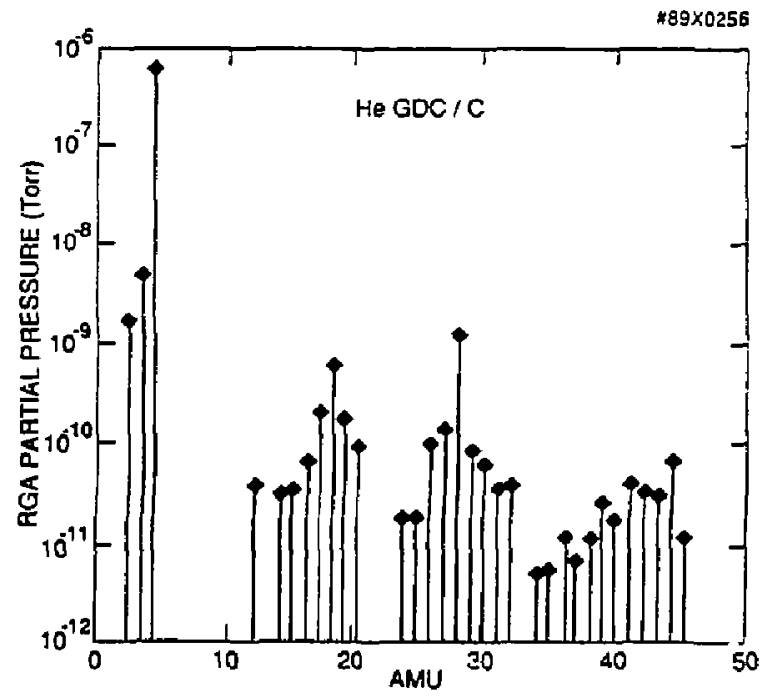

Fig. 5. Residual gas spectrum produced during helium GDC of TFTR with a carbon first wall.
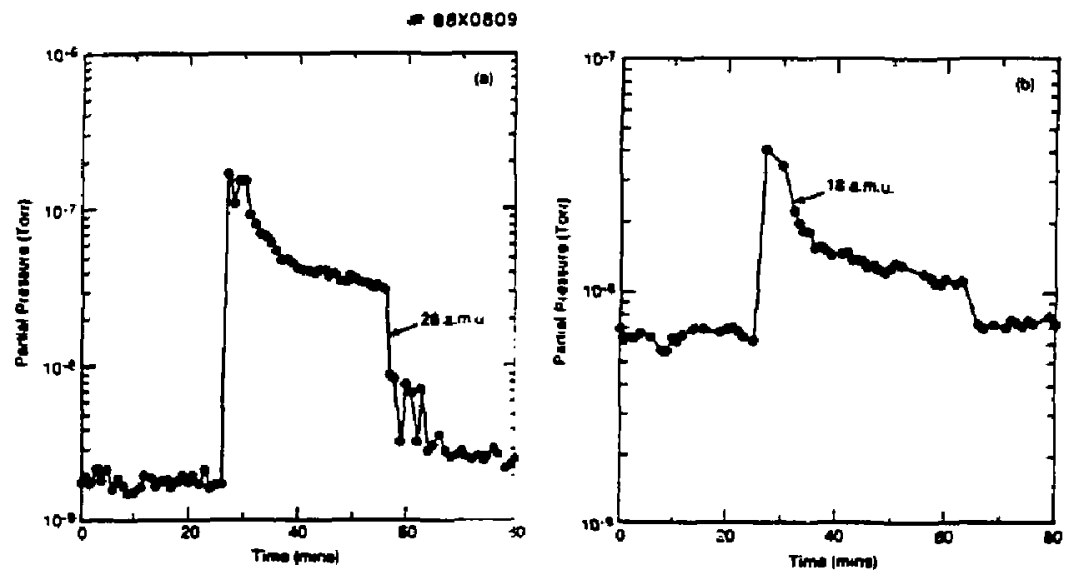

Fig. 6. Time dependence of $\mathrm{CO}$ (28 amu) and $\mathrm{H}_{2} \mathrm{O}$ (18 amu) production during helium GDC of TFTR with a carbon first wall. 


\section{REFERENCES}

1H. F. Dylla, J. Vac. Sci. Technol. A6. 1276 (1988).

2K. L. Wilson and W. L. Hsu, J. Nucl. Mater. 145-147, 121 (1987).

3J. Ehrenberg, J. Nucl. Mater. 162-164, 63 (1989).

4F. Waelbroeck, P. Wienhold, and J. Winter, J. Nuci. Mater. 111/112, 185 (1982).

5H. F. Dylla, S. A. Cohen, S. M. Rossnagel, G. M. McCracken, and Ph. Staib, J. Vac. Sci. Technol. 17, 286 (1980).

6P. Mioduszewski, R. E. Clausing, L. Heatherly, J. Nucl. Mater. 91,297 (1980).

7A. von Engle, Lonized Gases. 2nd Ed. (Oxford Press, London, 1965), p. 223.

BF. Waeibroeck, J. Winter, and P. Wienhold, J. Vac. Sci. Technol. A2, 1521 (1984).

9N. Noda, S. Hirokura, Y. Taniguckı, and S. Tanahashi, J. Vac. Sci. Technol. A1, 1430 (1983).

10K. Dimoff and A. K. Vijh, Surt. Technol. 25, 175 (1985).

11K. J. Dietz, I. Ali-Khan, F. Waelbroeck, and P. Wienhold, in Proc, of the NATO Adyanced Study Institute on Atomic and Molecular Processes in Thermonuclear Fusion (Plenum, New York, 1979).

12Ph. Staib, H. F. Dylla, and S. M. Rossnagel, J. Vac. Sci. Technol. 17, 291 (1980).

13H. F. Dylla, J. Nucl. Mater. 93/94, 61 (1980).

14R. R. Rye, Surtace Sci. 69,653 (1977).

15K. G. Tscherisch and J. von Seggern, in Proc, of the 5th Interr Sym, on Plasma Chemistry, Edinburgh, 1981, edited by B. Waidie.

16 A. G. Mathewson, A. Grillot, S. Hazeltine, K. Lee Li, A. Fuakes and H. Stori, in Proc, of the 8th Intern, Vacuum Congress, Cannes, 1980 (Le Vide, Paris, 1980), p. 395.

${ }^{17} \mathrm{H}$. F. Dylla, in Proce of the 6th Sym. on Plasma Processina, Vol. 86-6 in ECS Proc., edited by G. S. Mathad, G. C. Schwartz, and R. A. Gottscho (Electrochemical Society, Pennington, NJ, 1987), p. 18.

18 Soutterino by Particle Bombardment 1 . TAP 47, edited by R. Behrisch (Springer, Berlin, 1981).

$19 \mathrm{~J}$. Winter, J. Nucl. Mater. 145/147, 131 (1987).

20J. L. Cecchi, J. Nucl. Mater. $93 / 94,28$ (1980).

21 H. F. Dylla et al., J. Nucl. Mater. 155/157, 15 (1988).

22W. R. Wampler et al., J. Vac. Sci. Technol. A6. 211 (1988).

23A. E. Pontau and D. H. Morse, J. Nucl. Mater. 141-143, 124 (1986).

24H. F. Dylla et al., J. Nucl. Mater. 145-147 48 (1987).

25G. L. Jackson et al., J. Nucl. Mater. 162-164, 489 (1989).

${ }^{26} \mathrm{G}$. L. Jackson, Topical Conference on Surfacing Conditioning of Vacuum Systems, Los Angeles, CA, April 3-5, 1989.

27. Winter, Topical Conference on Surfacing Conditioning of Vacuum Systems, Los Angeles, CA, April 3-5, 1989. 
28. Grosman, J. Nucl. Mater. 162-164, 162 (1989).

$29 \mathrm{G}$. L. Schmidt, private communciation.

30H. F. Dylla et al., Nuci. Fusion 27, 1221 (1987).

31 H. F. Dylla et al., J. Nucl. Mater. 162-164, 128 (1989).

${ }^{32} \mathrm{H}$. F. Dylla and K. L. Wilson, Joint Princeton Plasma Physics Laboratory and Sandia National Laboratory Report No. PPPL-2523 and SAND 88-8212 (April 1988).

33J. Roth et al., J. Nucl. Mater. $93 / 94,601$ (1980).

34W. R. Wampler and S. M. Myers, J. Nucl. Mater. 111/112, 616 (1982).

35W. R. Wampler and B. L. Doyle, J. Nucl. Mater. 162-164, 1025 (1989).

36R. A. Langley, U. Vac. Sci. Technol. A6, 2119 (1988).

37 R. A. Langley, J. Nucl. Mater. 162-164, 1030 (1989).

$38 \mathrm{D}$. Mueller et al., Topical Conference on Surfacing Conditioning of Vacuum Systems, Los Angeles, CA, April 3-5, 1989. 
Dr. Frank J. Paolonl, Univ of wollongang, AUSTRALIA

Prof. M.H. Brennen, Univ Syoney, MUSTRALIA

Pfosmb Roseoren LaO., Australian Nat. Univ., AUSTRALiA

Prof. I.R. Jones, Flinders Univ., AUSTRal in

Prof. F, Cad, Inst Theo Phys, Austain

Prof. M. Hoinder, Instut fur Theoretische Physik, AUSTRIA

M. Goossons, Astronomiseh Instituut, BELGIUM

Ecole Royele Militaire, Lab de Phys Plasas, GELGIU

Comeission-Eurchean, Dg-X/1 Fusion Prog, BeLGiun

Prot, R, Bouciqua, Rijksun iversitelt Gent, BELGILm

Dr. P.H. Sokanaka, instifuto Fisico, GRAZli

Instituto De Pesquisas Espaciasi-INPE, BRnzIL

Documants Ortice, Atoric Energy of Canada Limited, CANADA

Dr. M.P. Bechynski, Mpg Technologies, Inc, , Cavada

Dr. H.M. Skarsgard, Universiry of Saskatcheman, CANMOA

Dr. H. Bernord, University of British Columoia, Cavan

Prof. J. Toicheann, Univ, of Montrest, Cavupa

Prof. S.R. Sreanivasan, University of Calgary, CNuDA

Prot. Tuoor w. Johnston, Ines-Energle, Cawan

Dr. Bolton, Cantre canadien a tusion magnétique, caknon

Dr. C.R. Jomes, Univ. of Alberta, Cawad

Dr. Puter Lukac, Kanenskeho Univ, CZECHOSLOYAKIA

The Librarian, Culnu Laboratory, EMGLND

The Librarian, Ruthertord Appleton Laboratory, ENGLAND

Mrs. S.A. Hutchinson, JET Library, ENGLAD

C. Moutter, Lab. Oe Physigue as milinux Ionisís, FRance

J. Rodat, CEH/CAOMRACHE - Bot 506 , FRUNCE

Hs. C. Rinni, Librarian, Univ. of loanning, GREECE

Dr. Tan Mal, Acadery Blbliographle Ser., how kong

Preprint Library, Hungarlen Acadmy af Scionces, Huwgaly

Dr. B. Des Gudeta, Sahs Inst of Nuel. Phys., InOIA

Dr. P. Kar, institute for Plasese Researen, Itoin

Or. Phillp Roseneu, Isreel inst. of Tech, ISRAEL

Librerion, Int'I Ctr Theo Phys, ITALY

Prof. G. Postagni, Istituto Gas lonlzzati Del CAR, ITALY

Migs Clelia De Palo, Assoc ELAuTOH-ENEA, ITALY

Dr. G. Grosso. Istituto di Fisica del Pl esmo. ITALY

Dr. M. romoro, Tosnibe Res o Dev, JAPAN
Prot, 1. Kawakami, Atomic Enorgy Res. Institute, JAPAN

Prot. Kyoji Nishikama, Uniu of itiroshima, JAPAN

Director, Dept. Lorge Tokamok Res. JAERI, JAPAN

Prof. Sotoshi Itoh, Kyushu University, JAPAN

Research into Conter. Nagoyo University. JAPAN

Prof. 5. Tanaka, Kyoto UnIversity, JAPAN

Library, Kyoto University, JAPAN

Prot. Nobuyuki I nove, University of Takyo, JAPAN

S. Mor $i$, JAER!, JAPAM

H. Juong, Librarian, Korea Advanced Enargy Ros inst, KOREA Prot. D.1. Choi, the Koreo Ady. Inst of Sci \& Tech, KOAEA

Prot. B.s. Liley, Univorsity of Woikoto, NEW ZEALANO Instituta of Plasma Physies, PEOPLE'S REPUEL IC OF CHINA Librarion, Institute of Phys., PEOPLE'S REPUBLIC OF CHIMA Liorery, Tsing Hu University. PEOPLE'5 REPUBLIC OF CHINA

2. Li, Southwest Inst. Ptysics, PEOPLE's REPUEL IC Of CHIMA Prot. J.A.C. CobraI, Inst 5uptrior Tecalico, PORTUGAL

Or. Octavian Petrus, AL I CUzA University, ROMANIA

Or. Joe do Filliars, Fusion Studies, AEC, SO AFRICA

Prof. M.A. Hellbarg. University of Natal, SO AFRICA

C.I.E.M.R.T., Fusion Div. Library. SPAIN

Dr. Lennsrt Stent10, University of UAEA, SAEDEK

Library, Royal Institute of Tech, 5WEDEN

Pror. Hors Wilhelimeon, Chalmers Univ of Tech, SWEDEN

Centre Phys des Plasaas, Ecole Polytech Fad, SHITZERLAro

Gibtiotheak, Fom-l inst voor Plasma-fysica, THE NETHERLAMOS

Matin Durgut, Middle East Toehnical University, TUAKEY

Dr. D.O. Ryutov, Siberian Acad SEi, USSR

Dr. G.A. Eliseev, Kurehatov Institute, US5R

Dr. V.A. Glukhikh, inst Electropnysical Apporotus, USSR

Prot. 0.5. Podichanko, Inst, of Phys. \& Toen. USSR

Dr. L.M. kovriznnykn, institute of Gen. Physies, USSR

Nuchear Res. Establ ishement, Julich Lta,., W. Gefownt

Bibliothak, Inst. Fur Plasmatorsehung, W. Gefahny

Or. K. Schindler, Ruhr-Uni versitat Bochum, W. GERauny ASDEX Reading Pan, c/O Wogner, IPPMax-PIonck, W. GERaunY Librarion, Moxflanck Institut, W. GEFawy

Prof. R.K. Jonov, Inst of Phys, rueoslavia 